\title{
Article
}

\section{Microsoft Teams and team performance in the COVID-19 pandemic within an NHS Trust Community Service in North-West England}

Hargreaves, Christopher, Clarke, Andy and Lester, Karl Robert Available at http://clok.uclan.ac.uk/40642/

Hargreaves, Christopher, Clarke, Andy ORCID: 0000-0003-4291-9851 and Lester, Karl Robert (2022) Microsoft Teams and team performance in the COVID-19 pandemic within an NHS Trust Community Service in North-West England. Team Performance Management .

It is advisable to refer to the publisher's version if you intend to cite from the work. http://dx.doi.org/10.1108/TPM-11-2021-0082

For more information about UCLan's research in this area go to http://www.uclan.ac.uk/researchgroups/ and search for <name of research Group>.

For information about Research generally at UCLan please go to http://www.uclan.ac.uk/research/

All outputs in CLoK are protected by Intellectual Property Rights law, including Copyright law. Copyright, IPR and Moral Rights for the works on this site are retained by the individual authors and/or other copyright owners. Terms and conditions for use of this material are defined in the policies page. 


\title{
Microsoft $^{\circledR}$ Teams and team performance in the COVID-19 pandemic within an NHS Trust Community Service in North-West England
}

\begin{abstract}
Purpose

This case study evaluates the impact the introduction of Microsoft ${ }^{\circledR}$ Teams has had on team performance in response to the COVID-19 pandemic within an NHS Community Service.

Design / Methodology / Approach

Microsoft ${ }^{\circledR}$ Teams was rolled out across the NHS over a period of four days, partly in response to the need for social distancing. This case study reviews how becoming a virtual team affected team performance, the role Microsoft ${ }^{\circledR}$ Teams had played in supporting staff to work in higher virtuality, understand what elements underpin a successful virtual team and how these results correlate to the Technology Acceptance Model (Davis, 1985).
\end{abstract}

\section{Findings}

The findings indicate that Microsoft ${ }^{\circledR}$ Teams made a positive impact to the team at a time of heightened clinical pressures and working in unfamiliar environments without the supportive benefits of face-to-face contact with colleagues in terms of incidental knowledge sharing and health and wellbeing.

\section{Originality}

Further developments were needed to make virtual meetings more accessible for introverted colleagues, support asynchronous communication, address training needs and support leaders to adapt and operate in higher virtuality.

Keywords: Team Performance; Community Service; Knowledge Sharing; Virtual Teams 
Understanding the impact Microsoft Teams has had on team performance in response to the COVID-19 pandemic within an NHS Trust Community Service in North-West England.

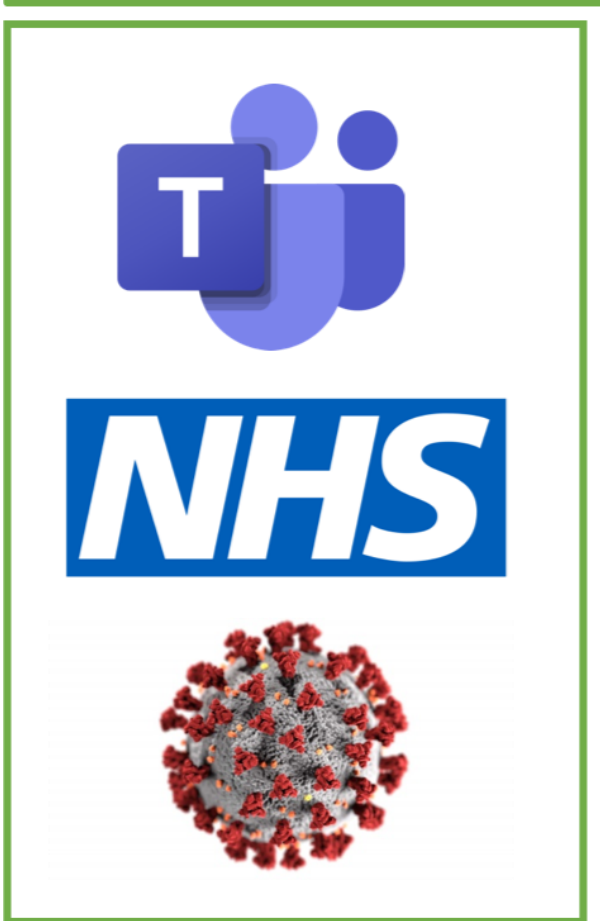

Microsoft Teams was introduced to an NHS team in response to Covid-19

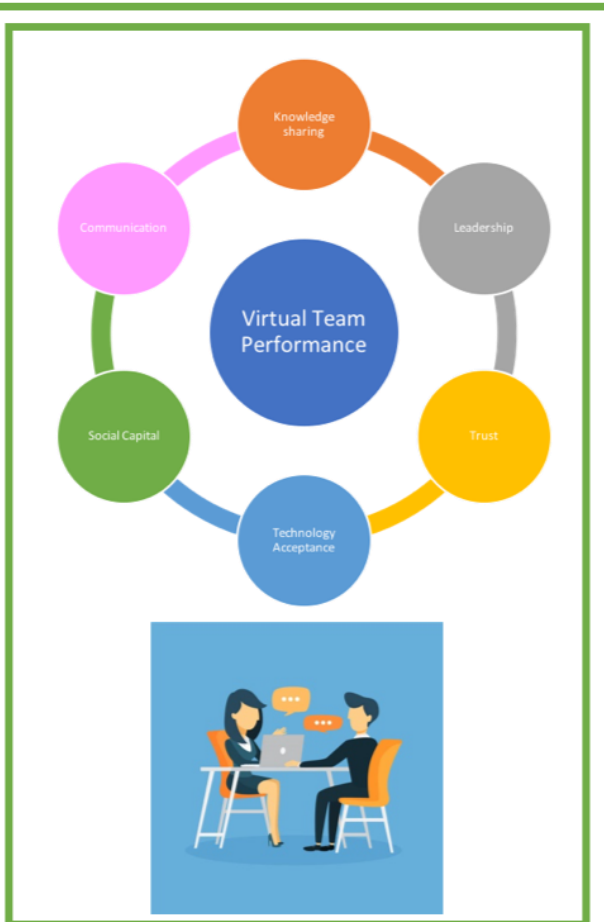

Literature review found key themes affecting virtual team performance, which were further explored with staff questionnaires \& interviews

Graphical Abstract

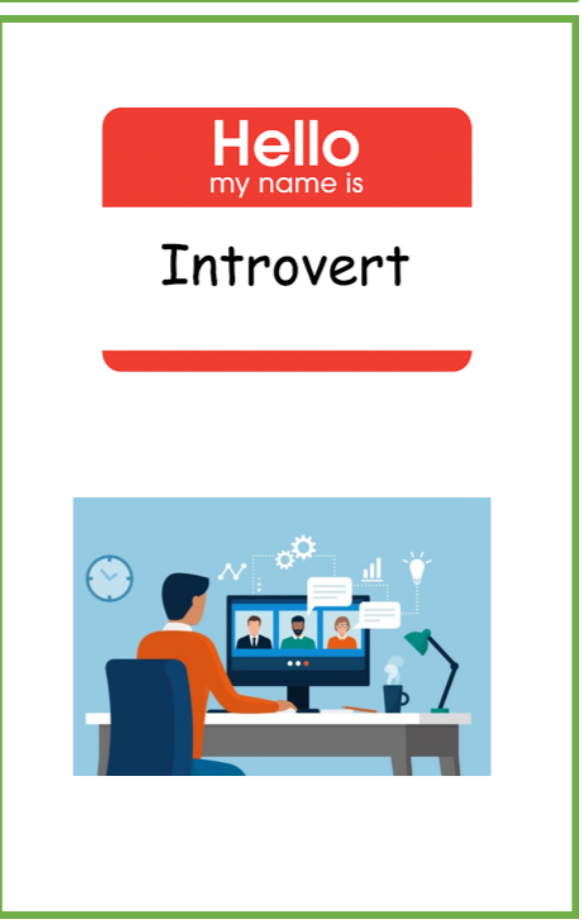

Research found that Teams had a positive impact in maintaining relationships during social distancing but introverts could be left behind and further training in 'e-leadership-was required 


\section{Introduction}

The NHS Community Service in this study is a multi-disciplinary, rapid-response service operating across East Lancashire. The aim of the Service is to prevent unnecessary hospital admissions by managing acute exacerbations of long-term conditions in the home environment and supporting early discharge by continuing treatments initiated in an acute setting in the patient's home. The Service comprises of 45 nursing, therapy, mental health and administrative staff, across a range of ages, genders, backgrounds and clinical experience.

\section{What is Microsoft ${ }^{\circledR}$ Teams?}

Microsoft ${ }^{\circledR}$ Teams (colloquially known as Teams) enables users to send instant messages, make internal calls, share, edit and collaborate on files and documents in one central, secure location (DigitalHealth, 2020). Microsoft ${ }^{\circledR}$ Teams enables staff to communicate from any location - via chat, voice or video calls/conferences (Khalili, 2020). Launched in 2017, Microsoft ${ }^{\circledR}$ saw the use of Teams grow exponentially during the COVID-19 pandemic. Taking the NHS utilisation of Teams in isolation, over 65 million messages have been sent and over 850,000 virtual meetings have been held between March-October 2020 (NHS Digital, 2020).

In response to the COVID-19 pandemic Microsoft ${ }^{\circledR}$ Teams was rolled out to all NHS users over a period of four days (Microsoft, 2020). COVID-19 has had a significant impact on a broad spectrum of industries with an obvious significant impact on healthcare. COVID-19 has catalysed alternative working methods (Clement et al., 2020), indeed in response to the pandemic, the NHS has responded and changed in ways and at a pace never seen before (Ford, 2020). Mehta et al. (2020) note a high demand for digital communication (including 
Microsoft ${ }^{\circledR}$ Teams) and this allows a rapid implementation with minimal costs in terms of resource.

\section{Background}

\section{Safety Huddles}

Prior to Teams being introduced to the service, staff would gather together each morning for a face-to-face 'safety huddle'. A safety huddle is a short multi-disciplinary briefing held at a regular time and place to discuss and identify patients most at risk. Not only do safety huddles focus on agreed actions and formulating plans of care, they also provide an opportunity to celebrate success (NHS Improvement, 2019).

When the need for social distancing arose, Microsoft $\mathrm{f}^{\circledR}$ Teams allowed the service to continue with daily safety huddles via video conference. Aside from supporting social distancing, this also allowed staff to start work from home, thereby reducing the amount of travelling required to get to their visits which in turn increased the amount of available clinical time per shift.

\section{Quality Improvements}

Prior to Teams, formulating, supporting and monitoring of quality improvements were heavily reliant on face-to-face meetings. As the service is based in a community health centre with only a few small meeting rooms, this meant staff regularly travelling to the local acute hospitals which had more suitable facilities. This in turn led to loss of clinician time as well as travel expenses. As quality improvements usually involved a number of different services, meetings were often delayed whilst staff availability could be aligned - an issue which was compounded by the need for staff to travel from different areas. 
In response to COVID-19, the commissioners looked to develop a new 'bolt-on' to the service named 'COVID Virtual Ward' to support COVID-positive patients to be remotely monitored at home. What would normally have required a 3-6 months project plan and rollout was achieved within 10 days and the initiative has been nationally recognised through winning a Health Service Journal Award. Teams allowed a range of staff to work on shared documents, facilitated by video conferences and screen sharing to expedite the process and gain input from a number of internal and external colleagues.

\section{Literature Review}

\section{Knowledge sharing}

Knowledge sharing can be defined as the mutual exchange of ideas and information which may influence the way teams learn in organizations (Shamsie \& Mannor, 2013). Virtual teams who can share knowledge effectively should expect increased cohesion, satisfaction and motivation within the team (Rosen et al., 2007). In virtual teams in particular, knowledge sharing is positively correlated with job effectiveness (Lin, 2011). Yet it is widely regarded that knowledge sharing is more difficult in a virtual setting than a traditional one (Ardichvili et al., 2003; Crandall and Gao, 2005).

\section{Technology Acceptance}

Holmes and Gardner (2006 p.14) raise the issue of the 'digital divide' which asserts that senior colleagues may not be as proficient in technology as junior members, stating "this may result in serious tensions in the workplace. Older staff can easily become alienated from the new technology". As virtual teams have a greater reliance on technology, lack of experience in the very applications which are meant to facilitate communication can create a barrier to communication (Bergiel et al., 2008). 
Central to understanding and overcoming the 'digital divide' is the Technology Acceptance Model (TAM), originally developed by Fred Davis in 1985. The model centres around two key variables - the perceived usefulness and the perceived ease of use.

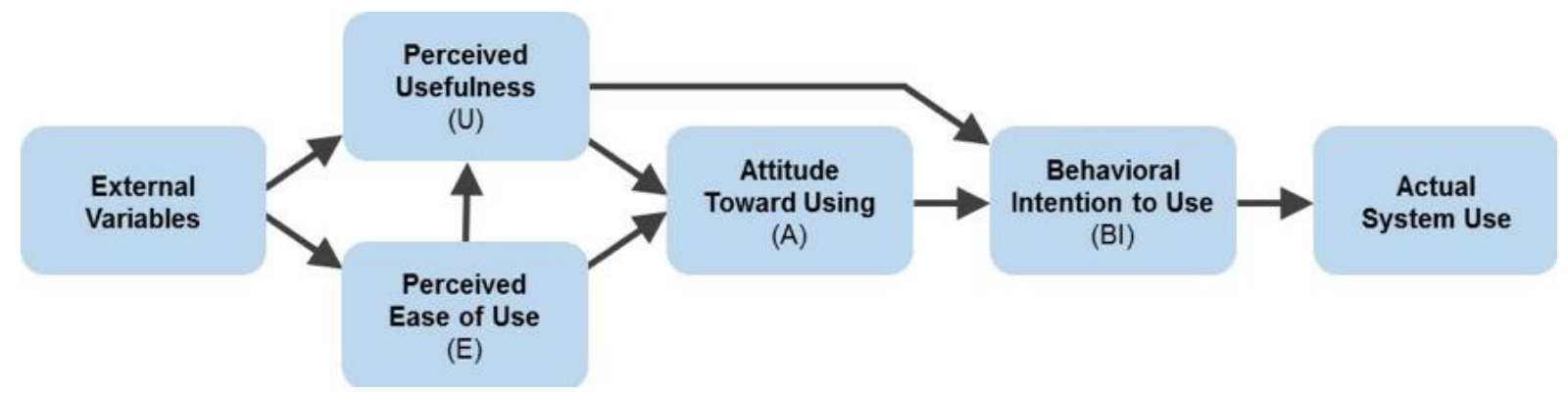

Figure 1: Technology Acceptance Model, Accessed at https://measuringu.com/tam/ on 19 January 2021

The key distinction to make with this model is the likelihood of any new technology being accepted by staff is purely down to perception. Therefore, if one staff member has a negative experience with the new technology this would affect the perceptions of other members of the team, regardless of the actual usefulness and ease of use of the system.

Dr Phil Candy, quoted in Collins (2007), previously National Education, Training and Development Director at NHS Connecting for Health said "You can have the best technology, the most advanced functionality possible, but if people don't want it - perhaps because they aren't equipped to use it - then it's in danger of falling flat." Technology acceptance and virtual competence then are key in embedding a new system within a team. Austin and Gregory (2021) note that team members how have confidence in the use of technology better manage workloads and feel in control of their tasks. Subsequent iterations of the Technology Acceptance Model such as the Unified Theory of Acceptance and Use of Technology (UTAUT) model have looked at whether technology introduction was voluntary or mandatory as a determinant on adoption. Due to the unique nature of adjusting to the working 
environment in light of the pandemic there was no choice but to make this a mandatory adoption as a means of maintaining lines of communication within the direct team and wider services.

\section{Social Capital}

The premise of social capital is based on social relationships which facilitate cooperation and collective action for mutual benefits (Bhandari and Yasunobu, 2009). In healthcare organisations specifically, social capital is positively correlated to risk management and quality of care, as well as improving employee well-being and satisfaction which in turn improves productivity, staff turnover and overall performance outcomes (Ansmann et al., 2020; Ali-Hassan et al., 2015).

Social capital is also central to quality improvement within teams. Heffernan (2015) writes "Without high degrees of social capital, you don't get the vigour of debate and exchange that hard problems demand. Creativity requires a climate of safety, but without social capital, no one will risk the fresh thought, the unpredictable idea, the testing questions... the best thinking partners don't confirm your opinions but build on them". It is important to note therefore, that conflict in a team is not necessarily a bad thing. It is for leaders to establish a climate and community where conflict is safe to explore. It is only then that teams will create their best, most robust, solutions.

However, it is important to note that whilst social capital is often developed over long term relationships, it can be quickly destroyed by trust-breaking behaviour (Striukova and Rayna, 2008). In virtual teams trust-breaking behaviour could be co-workers being slow to respond to messages or unwillingness to share knowledge (Feitosa and Salas, 2020).

Trust 
Trust is intertwined with knowledge sharing and social capital. If a team member does not trust a colleague then logic dictates that they would feel less comfortable, and less willing, to share their knowledge with them. If no trust exists colleagues would not start to build the social relationships on which social capital is formed and developed. When a good team trust culture exists, colleagues are more willing to discuss ideas and information without the concern of ridicule or embarrassment (Peñarroja et al., 2015).

In virtual teams, developing and maintaining trust becomes more difficult as virtual interactions lack social and physical cues such as facial expressions and tone of voice (Cheng et al., 2016). Issues of trust can be amplified as dynamics can be harder to read (Kings Fund, 2020).

For virtual teams, trust in the system used to facilitate virtual interactions can be just as important as trust between colleagues. System trustworthiness can be broken down to aspects such as performance (usefulness and effectiveness), design (ease of use) and assurance (security and reliability) (Choi and Cho, 2019). This has important significance for the Technology Acceptance Model, which does consider the system usefulness and ease of use but neglects to consider the concept of trust in the system as a factor in users accepting new technology.

\section{Team Dynamics / Isolation}

Whilst the requirements for social distancing meant that it was necessary to move towards higher virtuality within the team, working virtually can lead to social and professional isolation (Crandall and Gao, 2005). Informal chats between colleagues are not only important for trust building and knowledge sharing but are essential for physical and mental health (Kniffin et al., 2021). 
Research has found that in a typical meeting, an average of three people do $70 \%$ of the talking (Erwin, 2019), which neglects the input of more introverted colleagues. Throw into the mix the uncertainty of a new system, possibly a lack of confidence of how it works together with different ways of working and it only increases the likelihood of introverted colleagues keeping their contributions to themselves.

It is important therefore that leaders adjust their approach to virtual meetings and communications in general so as not to leave introverted colleagues behind. If not, 'group think' can occur where participants of meetings will simply agree with ideas so as not to cause conflict (Oeppen et al., 2020), consequently ideas are not challenged and therefore may not be the most suitable solution.

\section{Leadership}

In addressing all of the aforementioned aspects of virtual teams, it is clear that strong leadership is required in both managing and leading virtual teams. Cowan (2014 p.312) however states that "health care organizations have yet to appreciate the unique challenges associated with leading virtual teams. More than ever, nurse leaders are faced with managing some aspect of virtual teams that require a new way of leading." Yet less than $20 \%$ of virtual teams receive training on how to work effectively as a virtual team (Lepsinger and DeRosa, 2015). It is important to note that when responding to a global pandemic, training needs can, understandably, be neglected; but if virtual working is to continue post-pandemic, training in how to be an effective virtual team member and leader should be considered a high priority. This new way of leading, or 'e-leadership', has been defined by Avolio and Kahai (2010 p.239) as "a process of social influence that takes place in an organizational context where a significant amount of work, including communication, is supported by IT". Consequently, successful e-leaders need to utilise and harness the technology as a vehicle for 
exerting social influence over their team to convey shared understanding and deliver their vision and values.

Whilst it is acknowledged that there is no singular leadership style for managing in a virtual environment (Farmer, 2005), effective leaders must demonstrate a flexible approach and adapt their leadership style to the situation. In doing so, leaders must involve the team in establishing what the 'new normal' looks like, being transparent about decision making and empowering team members to participate (Feitosa and Salas, 2020). For example a leader could involve the team in developing 'house rules' for virtual meetings, such as the use of plain backgrounds so as not to distract from conversation and the need for punctuality in attending virtual meetings (Kings Fund, 2020).

The author posits the idea of virtual team performance affecting and also being affected by knowledge sharing, leadership, trust, technology acceptance, social capital and communication (Figure 2).

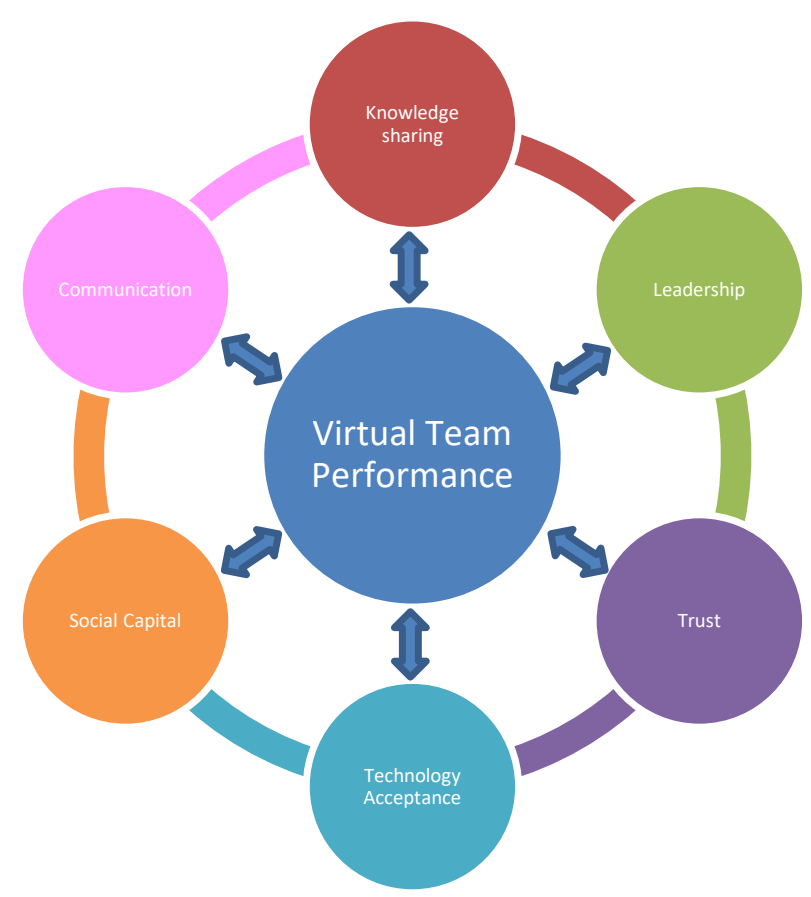

Figure 2: Factors affecting virtual team performance (developed by author for the study) 


\section{Methodology}

\section{Phase One}

A questionnaire designed by the researcher where 13 questions were organised into 6 themes. The questionnaire used a combination of open-end questions and questions which asked for a response using a 4-point Likert scale (Saunders et al., 2019). 45 participants (the size of the team) were invited to take part in this study and therefore did not impose bias into the results; 27 of those 45 responded, therefore $n=27$.

\section{Phase Two}

A semi-structured interview with the Clinical \& Operational Lead was used $(n=1)$.

\section{Questionnaire Questions}

Age groups and grade:

To what extent do you agree or disagree with the statements below:

1. Microsoft ${ }^{\circledR}$ Teams has supported knowledge sharing within the team during COVID

2. Microsoft ${ }^{\circledR}$ Teams is embedded within the team

3. Working remotely during COVID has had a negative impact on communication within the team

4. Microsoft ${ }^{\circledR}$ Teams has helped to support communication within the team during COVID

5. Microsoft ${ }^{\circledR}$ Teams is easy to use

6. Microsoft ${ }^{\circledR}$ Teams supports me in my work

7. Microsoft ${ }^{\circledR}$ Teams has helped support camaraderie within the team during COVID

8. I am confident in using Microsoft ${ }^{\circledR}$ Teams at work 
9. I would benefit from further training Microsoft ${ }^{\circledR}$ Teams

10. I feel confident in contributing to meetings via Microsoft ${ }^{\circledR}$ Teams

11. If social distancing finishes, I would prefer to return to face-to-face meetings

12. Microsoft ${ }^{\circledR}$ Teams has increased accessibility to senior staff

13. How could the service make better use of Microsoft ${ }^{\circledR}$ Teams?

\section{Interview Questions}

1. What impact has COVID has on the service?

2. So what is your experience of Teams since it came in at the beginning of the pandemic?

3. So how has it supported you in your work, in your role?

4. So what impact do you think Teams has had on the service?

5. People tend to go 'I'll Teams you...

6. Do you think meetings over Teams are as effective as face-to-face discussions?

7. Do you think Teams has supported knowledge sharing?

8. Do you think Teams has been accepted by staff?

9. What effect do you think Teams has had on patient discussions?

10. What effect do you think Teams has had on staff discussions in terms of team spirit, team meetings, that sort of thing?

11. So if social distancing finishes, would you like to see a return to face-to-face meetings?

12. And lastly, how do you think we could improve the use of Teams in the service?

\section{Ethical considerations}

As the researcher is situated in the Community Service, it is vital that trust with colleagues is not negatively impacted by misleading or pressuring team members. Participants receive 
complete anonymity; the researcher gained informed consent by communicating the purpose of the case study as well as detailing how their data will be processed. Completion of the questionnaire is not mandatory, and participants have the option to exit the questionnaire at any point where that participant data is destroyed.

In phase two, informed consent was again gained; the participant was free to pause or end the interview at any time.

The case study was determined to be a service evaluation project and therefore did not require Health Research Authority (HRA) ethical review, however approval was received from the Trust Research and Development Team.

\section{Findings}

Phase 1 - Staff questionnaire

The questionnaire was distributed to all 45 staff in the team and 27 responses were received, equating to a response rate of $60 \%$ which is typical of an employee questionnaire (Walker, 2012) and 13\% higher than the most recent NHS staff survey (NHS Staff Survey, 2020). This indicates the questionnaire was both accessible to staff members and was a topic which was sufficiently interesting and relevant to respond to. The results of the questionnaire are summarised in Table 1.

\begin{tabular}{|c|c|c|c|c|}
\hline Statement & 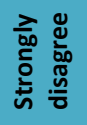 & 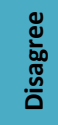 & 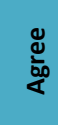 & 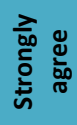 \\
\hline Microsoft ${ }^{\bullet}$ Teams has supported knowledge sharing within the team during COVID & 0 & 2 & 17 & 8 \\
\hline Microsoft $^{\circ}$ Teams is embedded within the team & 0 & 0 & 14 & 13 \\
\hline Working remotely during COVID has had a negative impact on communication within the team & 8 & 11 & 7 & 1 \\
\hline Microsoft ${ }^{\circ}$ Teams has helped to support communication within the team during COVID & 0 & 2 & 11 & 14 \\
\hline Microsoft $^{\circ}$ Teams is easy to use & 0 & 0 & 16 & 11 \\
\hline Microsoft $^{\circ}$ Teams supports me in my work & 0 & 3 & 12 & 12 \\
\hline
\end{tabular}




\begin{tabular}{|c|c|c|c|c|}
\hline Microsoft $^{\circ}$ Teams has helped support camaraderie within the team during COVID & 0 & 5 & 17 & 5 \\
\hline I am confident in using Microsoft ${ }^{\circ}$ Teams at work & 0 & 2 & 13 & 12 \\
\hline I would benefit from further training in Microsoft ${ }^{\circ}$ Teams & 2 & 13 & 11 & 1 \\
\hline I feel confident in contributing to meetings via Microsoft ${ }^{\circ}$ Teams & 0 & 2 & 16 & 9 \\
\hline If social distancing finishes, I would prefer to return to face-to-face meetings & 7 & 8 & 9 & 3 \\
\hline Microsoft ${ }^{\circ}$ Teams has increased accessibility to senior staff & 0 & 7 & 12 & 8 \\
\hline How could the service make better use of Microsoft ${ }^{\circ}$ Teams? (free-text responses) & - & - & - & - \\
\hline
\end{tabular}

Table 1: Questionnaire Results

\section{Questionnaire engagement}

The gender of participants was not analysed as there are minimal male members of staff and therefore would be easily identifiable. The age profile of participants demonstrates that whilst $50 \%$ of the $25-34$ and $45-54$ year olds in post within the team responded, there was underrepresentation from the 35-44 year old group (32\%) and over-representation from the 55-64 year old group (57\%).

Whilst there was high engagement from band $3(100 \%)$, band $7(86 \%)$ and band 8 a (66\%), there were lower levels of engagements with band $4(55 \%)$ and band 6 staff $(48 \%)$. This may be due to band 4 and 6 staff undertaking the majority of clinical visits and therefore not having the same amount of time available for clerical duties meaning less opportunity to complete the questionnaire.

\section{Phase 2- Clinical Lead Interview}

Incorporating the learning from the staff questionnaire, a semi-structured interview was held with the Clinical Lead for the service; the responses are presented in themes in line with the factors affecting virtual team performance: knowledge sharing; technology acceptance; communication; social capital; trust and leadership.

\section{Discussion}




\section{Staff Questionnaire}

\section{Knowledge sharing}

Results from the questionnaire indicated that Microsoft ${ }^{\circledR}$ Teams had helped to support knowledge sharing with $93 \%$ of respondents agreeing or strongly agreeing. However looking beyond the quantitative data, Respondent 3 noted that "if you miss the morning (safety) huddle, you miss a lot of information. It might be given out verbally but there is no record for people who have missed it to look back." Several other comments made reference to the recording and sharing of key information, therefore it may be possible to further facilitate knowledge sharing by exploring methods to summarise and share key points of discussion from Teams huddles.

\section{Technology Acceptance}

The Technology Acceptance Model (Davis, 1985) suggests that for new technology to be embraced and embedded by users, they must perceive it to be both easy to use and useful. This was examined during the questionnaire with $100 \%$ of participants agreeing that Teams is easy to use (59\% agree, $41 \%$ strongly agree) and $89 \%$ of participants believing Teams supports them in their work ( $44 \%$ agree, $44 \%$ strongly agree), thereby indicating that Teams has been accepted by the team as a new technology (aligning to Choi and Cho, 2019). This supports the TAM variables of Perceived Usefulness and Perceived Ease of Use. $100 \%$ of participants believed teams was embedded within the team with Respondent 6 stating "Teams became a different way of working for us almost overnight. Being able to liaise with different teams at the touch of a button has been really helpful." Teams was introduced at a time where it enabled users to maintain lines of communication with colleagues in light of social distancing and higher virtuality; this helped Teams become an accepted technology for users. This supports the TAM variables of Attitude Toward Using and Behavioural Intention to Use. 


\section{Communication}

There were mixed views as to whether working remotely has had a negative impact on communication within the team, with $30 \%$ strongly disagreeing, $41 \%$ disagreeing, $26 \%$ agreeing and only $4 \%$ strongly agreeing. Whilst the consensus $(71 \%)$ disagreed that working remotely had a negative impact, this question provided one of the most mixed responses. One of the additional comments may provide an insight into the reasons behind this as Respondent 12 stated "communication regarding patient care has continued but the loss of team meetings and clinical supervision has meant there is a lack of cascade of other information". Therefore it may be that communication per se was too generic a term to use and this should have been broken down into component parts such as patient communication or team communication etc. This was supported by the mixed response when participants were asked if they would prefer to return to face-to-face meetings if social distancing finishes with a 56/44 marginal preference in favour of not returning to face-to-face meetings. When reviewing the responses in more detail, some participants (Respondent 13) who did not want to return to face-to-face meetings still saw the value in them, stating "I feel the huddles work very well on Teams and promote remote working. However, I feel face-to-face team meetings are also important in the team". This supports the TAM variables of Attitude Toward Using and Behavioural Intention to Use.

Whilst participants agreed that Microsoft ${ }^{\circledR}$ Teams had helped to support communication within the team during higher virtuality, a number of comments made reference to how the loss of face-to-face communication had impacted them such as (Respondent 2) "I think previously I picked up more on changes through conversations in the office which do not tend to happen as frequently now" and (Respondent 5) "Whilst we do have Teams, nothing can replicate a face-to-face conversation. Picking up on bits of conversations in the office is difficult to replicate on Teams". 
It may be that Teams, whilst providing the rudimentary function to maintain communication during higher virtuality, has done nothing to enhance communication. This is supported by the language used by Respondent 13 who stated "Teams has definitely helped to bridge the gap whilst we've had to socially distance".

\section{Social Capital / Trust}

Participants were asked whether Teams has helped support camaraderie during COVID as a means of gauging the impact of increased virtuality on social capital. Whilst the majority (81\%) of participants agreed or strongly agreed that Teams has been a support, 19\% disagreed with the statement. Respondent 13 stated that "sometimes it's difficult to read people over Teams". This asserts that trust becomes more difficult to maintain through virtual interactions and dynamics can become harder to read (Cheng et al., 2016; Kings Fund, 2020).

The importance of 'virtual handshakes' and 'getting your voice in the room' as a conduit to building and maintaining trust between colleagues was also reinforced by participants (Respondent 20) who stated "I sometimes find it difficult to speak up in meetings... sometimes you aren't heard then the discussion continues onto another topic." By excluding the more introverted members of the team or reducing opportunities for staff to contribute in general, 'group think' occurs whereby members of the meeting agree with the consensus of opinion and different, potentially better, solutions are neglected.

\section{Leadership}

Participants were asked whether Teams had increased accessibility to senior staff; the majority of participants (74\%) either agreed or strongly agreed that accessibility had increased. There was also praise for how meetings were led, with several respondents noting how Teams discussions were more "focused", "efficient", "productive" and "better managed" than face-to-face meetings. Feedback from some respondents regarding difficulty in speaking 
up would suggest that the efficiency of meetings has come at the expense of fewer contributions from the more introverted team members. These factors indicate that TAM is one element to a successful team, and not the overall model in itself.

\section{Clinical Lead interview}

\section{Knowledge sharing}

The impact of Teams on knowledge sharing was believed to be positive, noting the immediacy which Teams offers:

“Now when we've got questions, we can just... log in, dial in via Teams and we've got access straight away."

Teams also facilitated knowledge sharing across organisations, with the Clinical Lead citing a recent example:

"You can bring in people from out of area into your meetings to share knowledge and experience... We recently had a meeting with West Kent to discuss their service and future developments... if we were going to do that previously if would've been via telephone or travel over to Kent... and an overnight stay."

Further work needs to be done in terms of sharing knowledge in a more literal sense:

"We need to get better at sharing information via Teams, sharing your documents, sharing your agendas.”

This echoed the staff questionnaire where $93 \%$ of respondents believed Teams supported knowledge sharing but staff felt they would benefit from a more consistent method of sharing information and updates with the team.

\section{Technology Acceptance}


The questionnaire suggested that Teams had been accepted by staff and this was supported with the views shared in the interview, whilst noting some understandable initial apprehension:

"Initially people were apprehensive regarding Teams... now its second nature. People 'Teams' all the time even if it's not an expected meeting or a formal meeting."

The language used by the interviewee that people 'Teams' all the time is telling, as it suggests that Teams has become engrained in the language and culture of the team. This view was supported by comments such as:

"I think people would struggle now if it was taken away. I don't think we'd back to original means of communication."

"It's facilitated people working from home... but it's also made things more productive, it's saved on travel time, it's reduced expenses and created more capacity... for face-to-face contacts with patients."

Further training is required to fully realise the benefits which Teams offers:

"Whilst we send invites out for most meetings there are still staff that are reluctant to accept invites so it's a case of dialling them in individually... I think we have to build confidence for staff."

This view was supported in the questionnaire feedback, as $45 \%$ of staff felt they would benefit from additional training. These results support TAM and show that the variables of Perceived Usefulness and Perceived Ease of Use support Attitude Toward Using and Behavioural Intention to Use, which lead into Actual System Use.

\section{Communication}


Much of the discussion around communication centred on how Teams has facilitated a widening of the traditional circles of communication:

"Teams has facilitated patient discussions. We frequently dial into other healthcare professionals... to have those discussions, be able to engage in a multi-disciplinary approach to discuss patient care and invite the correct professionals into those meetings on Teams, so it's improved patient access in regard to getting a multi-professional team around the table."

"We can reach a bigger audience than what we could've done ordinarily, and we tend to get more attendance at the meetings because people just need to dial in rather than consider the travel."

Improving access to a variety of opinions and specialisms can only enhance the care and treatment afforded to patients, but concerns were raised in relation to staff communication:

"That for me is one of the negative impacts of Teams because you don't have that interpersonal connection... Sometimes it's just nice to get together in a room and see people face-to-face and have more of an interpersonal discussion."

These thoughts were mirrored in the questionnaire feedback where participants noted the value of face-to-face contact and called for a return to some degree of face-to-face meetings. It may be that a blended approach is required in order to achieve the balance between the convenience and efficiencies provided by Teams meetings, against the personal connection found in face-to-face meetings.

\section{Social Capital / Trust}

The interviewee supported the previously cited research of Newark et al. (2017) which found that individuals are more willing to help and display prosocial behaviour during crises: 
"Whilst in a very negative time, it meant that we developed our team, pulled together, increased team morale, managed to develop a COVID rapid response service where we took referrals direct for monitoring. We took almost 2000 additional referrals through the service in a 5-month period, and all that extra work was picked up by existing staff... overall it had a positive impact on the service."

Microsoft ${ }^{\circledR}$ Teams was key to the rapid development of the COVID rapid response service as it allowed commissioners, primary and secondary care colleagues to collaborate at the touch of a button, sharing and developing pathways and policies - all whilst maintaining social distancing. For all the benefits which Teams brings, the importance of face-to-face contact was a running theme throughout the interview, with comments such as:

"I do feel that it is important, that as a team, you manage to get that face-to-face time to improve bonding and team spirit."

\section{Leadership}

Microsoft ${ }^{\circledR}$ Teams was seen in a positive light with regards to leadership. With references made to being more accessible to staff and availability to wider services:

"It's allowed me to access more... more meetings in the day that I would ordinarily be able to do because I wouldn't be able to travel to access the places that I need to be at."

Previously cited research noted that more introverted colleagues may be left behind with virtual meetings, which can lead to this cohort becoming marginalised and not contributing to the team. The feedback from the questionnaire supported this view as staff noted that it can be difficult to speak up in meetings. This view was also supported by the interviewee:

“... when you're discussing things with more junior staff or people outside the organisation ... the bigger the arena, the more afraid people appear to be to raise issues." 
This has clearly been recognised as an issue, and the Clinical Lead offers a potential solution:

"... picking up on that within the meeting, it then facilities you to contact those people, on a smaller... in a smaller forum or in a one-to-one basis to have that communication which is ultimately better for them."

Whilst this approach should be congratulated, the feedback from the questionnaire still indicates that more introverted colleagues are finding it difficult to contribute to meetings so it may be that this approach is not commonplace throughout the team, or that these colleagues would prefer to have the opportunity to contribute whilst in the larger forum. This can be facilitated by the chair of the meeting facilitating opportunities to allow staff to 'get their voice in the room'.

The elements which underpin a successful virtual team include: knowledge sharing; leadership; trust; technology acceptance; social capital and communication. These elements are not independent of each other and often overlap, meaning that if one element is underperforming it will affect the overall performance of the team. The variables in TAM have been validated, however for a successful team the wider elements noted are essential.

\section{Benefits}

Microsoft ${ }^{\circledR}$ Teams helped to effectively 'plug the gap' and provide a conduit to allow communication, knowledge sharing and maintain the personal and professional ties developed between colleagues over time. Teams was introduced at rapid pace and with minimal training but has been accepted as both useful and easy to use by colleagues. Teams has also supported collaboration and knowledge sharing across both internal and external services and provided efficiencies in terms of clinical time and travel expenses.

\section{Drawbacks}


Introverted colleagues found it difficult to contribute to meetings and 'get their voice in the room'. Whilst this was recognised and addressed to a degree by the Clinical Lead for the service, not all meeting chairs would have the same awareness and actively seek opinions from colleagues where it was not immediately forthcoming. This can lead to 'group think' where team members will agree with the majority opinion and may lead to colleagues feeling excluded from the team which will impact a number of areas, not least the health and wellbeing of staff if they do not have access to the same support networks.

Opportunities for incidental learning are negatively impacted whilst working in increased virtuality. The 'corridor conversation' or the proverbial 'chat by the watercooler' are not easily replicated on Microsoft ${ }^{\circledR}$ Teams. This was borne out in the quantitative element of the study which found colleagues who missed the daily video meetings felt they were quickly out of the loop.

\section{Conclusions}

The variables in TAM have been validated, however in addition there are a number of conclusions to be drawn from this study:

- Recognise the role informal / incidental learning plays

In a collocated team, both the academic and primary research indicates that knowledge sharing is osmosis-like and happens naturally. When working virtually, knowledge sharing becomes more difficult and almost has to become an explicit, planned task. In a virtual team, leaders should consciously create opportunities for colleagues to come together in both formal and informal forums to allow knowledge sharing to occur.

- Do not leave the introverted colleagues behind 
A team is made up of people with a range of age, experience, skills and personality types. Left unaddressed, the more introverted colleagues can easily be left behind in a virtual team. Introverts often have well-thought, considered views to contribute to discussions and if these are lost not only will this have a detrimental effect on team performance, but these same colleagues will become disenfranchised and demotivated. It is therefore crucial for leaders to address this and find opportunities to include introverted colleagues and allow them to 'get their voice in the room'.

- A new way of leading

'E-leadership' is still in its infancy. COVID-19 has changed the landscape of the traditional working patterns/practices across the world almost overnight and in doing so has dramatically accelerated the need for leaders to develop e-leadership as a tool in their arsenal. It is the author's belief that whilst some level of normality will return to workplaces over the coming months and years, working from home or hybrid working arrangements will become commonplace and therefore the modern leader will need to adapt to understand the intricacies that come with leading a successful, high-performing virtual team.

\section{References}

Ali-Hassan, H., Nevo, D., and Wade, M. (2015). Linking dimensions of social media use to job performance: The role of social capital. The Journal of Strategic Information Systems. 24 (2), p65-69. doi:10.1016/j.jsis.2015.03.001

Ansmann, L., Hower, K.I., Kowalski, C., Ernstmann, N., McKee, L. and Pfaff, H. (2020). Measuring social capital of healthcare organizations reported by employees for creating positive workplaces - Validation of the SOCAPO-E instrument. BMC Health Services Research. 20 (272), p1-10. doi:10.1186/s12913-020-05105-9 
Ardichvili, A., Page, V. and Wentling, T. (2003). Motivation and barriers to participation in virtual knowledge-sharing communities of practice. Journal of Knowledge Management. 7 (1), p64-77. doi:10.1108/13673270310463626

Austin, Z., \& Gregory, P. (2021). Resilience in the time of pandemic: The experience of community pharmacists during COVID-19. Research in Social \& Administrative Pharmacy, 17(1), 1867-1875. doi: 10.1016/j.sapharm.2020.05.027

Avolio, B. and Kahai, S. (2010). E-leadership. In: Hickman, G.R Leading organizations. Perspectives for a new era. 2nd ed. Thousand Oaks, CA: SAGE Publications. p239-244. Bergiel, B.J., Bergield, E.B. and Balsmeier, P.W. (2008). Nature of virtual teams: a summary of their advantages and disadvantages. Management Research News. 31 (2), p99-110. doi:10.1108/01409170810846821

Bhandari, H. and Yasunobu, K. (2009). What is social capital? A comprehensive review of the concept. Asian Journal of Social Science. 37 (3), p480-510. doi:10.1163/156853109x436847

Cheng, X., Fu, S., Sun, J., Han, Y., Shen, J. and Zarifis, A. (2016). Investigating individual trust in semi-virtual collaboration of multicultural and unicultural teams. Computers in Human Behavior. 62 (September 2016), p267-276. doi:10.1016/j.chb.2016.03.093

Choi, O. and Cho, E. (2019). The mechanism of trust affecting collaboration in virtual teams and the moderating roles of the culture of autonomy and task complexity. Computers in Human Behavior. 91 (2019), p305-315. doi:10.1016/j.chb.2018.09.032

Clement, K.D., Zimmermann, E.F., Bhatt, N.R., Light, A., Gao, C., Kulkarni, M., Norris, J.M., Gallagher, K.M.J., Cambridge, W.A., Shah, T.T., Ratan, H.L., Smith, D., Kasivisvanathan, V. (2020). Communication tools in the COVID-19 era and beyond which 
can optimise professional practice and patient care. British Medical Journal Innovation. 0, p1-7. doi:10.1136/bmjinnov-2020-000465

Collins, T. (2007). Memorable quotes - Dr Phil Candy, a Director at NHS Connecting for Health. Available: https://www.computerweekly.com/blog/Public-Sector-IT/Memorablequotes-Dr-Phil-Candy-a-Director-at-NHS-Connecting-for-Health. Last accessed 19th January 2021.

Cowan, L.D. (2014). e-Leadership: Leading in a Virtual Environment - Guiding principles of nurse leaders. Nursing Economics. 32 (6), p312-322.

Crandall, W.R. and Gao, L. (2005). An Update on Telecommuting: Review and Prospects for Emerging Issues. S.A.M. Advanced Management Journal. 70 (1), p30-37.

DigitalHealth. (2020). Microsoft Teams to be rolled out across NHS in response to coronavirus. Available: https://www.digitalhealth.net/2020/03/Microsoft-teams-nhscoronavirus/. Last accessed 14th November 2020.

Erwin, M. (2019). 6 reasons we make bad decisions, and what to do about them. Available: https://hbr.org/2019/08/6-reasons-we-make-bad-decisions-and-what-to-do-about-them. Last accessed 7th February 2021.

Farmer, L. (2005). Situational leadership: A model for leading telecommuters. Journal of Nursing Management. 13 (6), p483-489. doi:10.1111/j.1365-2934.2005.00573.x

Feitosa, J. and Salas, E. (2020). Today's virtual teams: Adapting lessons learned to the pandemic context. Available: https://www.ncbi.nlm.nih.gov/pmc/articles/PMC7311332/. Last accessed 2nd February 2021. 
Ford, G. (2020). The pandemic has shown the NHS can adopt and drive change rapidly. Available: https://www.ahsnnetwork.com/the-pandemic-has-shown-the-nhs-canadopt-and-drive-change-rapidly. Last accessed 14th November 2020.

Heffernan, M. (2015). The secret ingredient that makes some teams better than others. Available: https://ideas.ted.com/the-secret-ingredient-that-makes-some-teams-betterthan-others/. Last accessed 6th February 2021.

Holmes, B. and Gardner, J. (2006). E-learning: concepts and practice. London: Sage.

Khalili, J. (2020). What is Microsoft Teams? How it works, latest features and top alternatives. Available: https://www.techradar.com/uk/news/what-is-Microsoft-teams-how-itworks-tips-and-tricks-and-best-alternatives. Last accessed 15th November 2020.

Kings Fund. (2020). Leading teams virtually. Available:

https://www.kingsfund.org.uk/publications/leading-teams-virtually. Last accessed 6th February 2021.

Kniffin, K.M, Narayanan, J., Anseel, F., Antonakis, J., Ashford, S.P., Bakker, A.B., Bamberger, P., Bapuji, H., Bhave, D.P., Choi, V.K., Creary, S.J., Demerouti, E., Flynn, F.J., Gelfand, M.J., Greer, LL., Johns, G., Kesebir, S., Klein, P.G., Lee, S.Y., Ozcelik, H., Petriglieri, J.L., Rothbard, N.P., Rudolph, C.W., Shaw, J.D., Sirola, N., Wanberg, C.R., Whillans, A., Wilmot, M.P., Bugt, M.V. (2021). COVID-19 and the workplace: Implications, issues, and insights for future research and action. The American Psychologist. 76 (1), p6377. doi:10.1037/amp0000716

Lepsinger, R. and DeRosa, D. (2015). How to Lead an Effective Virtual Team. Available: https://iveybusinessjournal.com/how-to-lead-an-effective-virtual-team/. Last accessed 7th February 2021. 
Mehta, J., Yates, T., Smith, P., Henderson, D., Winteringham, G. and Burns, A., (2020). Rapid implementation of Microsoft Teams in response to COVID-19: one acute healthcare organisation's experience. BMJ health \& care informatics, 27(3).

Microsoft. (2020). NHS staff can use Microsoft Teams for free amid Coronavirus outbreak. Available: https://news.Microsoft.com/en-gb/2020/03/19/nhs-staff-can-useMicrosoft-teams-for-free-amid-coronavirus-outbreak/. Last accessed 14th November 2020.

Newark, D., Bohns, V. and Flynn, F. (2017). A helping hand is hard at work: Underestimating help quality. Organizational Behavior and Human Decision Processes. 139 (1), p223-226. doi:10.1016/j.obhdp.2017.01.001

NHS Digital. (2020). MS Teams use in the NHS soars as pandemic continues. Available: https://digital.nhs.uk/news-and-events/news/ms-teams-use-in-the-nhs-soars-as-pandemiccontinues. Last accessed 15th November 2020.

NHS Improvement. (2019). Safety huddles. Available: https://improvement.nhs.uk/resources/safety-huddles/. Last accessed 19th January 2021. NHS Staff Survey. (2020). NHS Staff Survey Results - 2020. Available: https://www.nhsstaffsurveyresults.com/homepage/results-2020/. Last accessed 31st March 2021.

Oeppen, R.S., Shaw, G. and Brennan, P.A. (2020). Human factors recognition at virtual meetings and video conferencing: how to get the best performance from yourself and others. British Journal of Oral and Maxillofacial Surgery. 58 (1), p643-646. doi:10.1016/j.bjoms.2020.04.046 
Peñarroja, V., Orengo, V., Zornoza, A., Sánchez, J. and Ripoll, P. (2015). How team feedback and team trust influence information processing and learning in virtual teams: A moderated mediation model. Computers in Human Behavior. 48 (2015), p9-16. doi:10.1016/j.chb.2015.01.034

Rosen, B., Furst-Holloway, S. and Blackburn, R. (2007). Overcoming Barriers to Knowledge Sharing in Virtual Teams. Organizational Dynamics. 36 (3), p259-273. doi:10.1016/j.orgdyn.2007.04.007

Saunders, M., Lewis, P. and Thornhill, A (2019). Research Methods for Business Students. 8th ed. Harlow: Pearson Education Limited.

Shamsie, J. and Mannor, M. (2013). Looking Inside the Dream Team: Probing Into the Contributions of Tacit Knowledge as an Organizational Resource. Organization Science. 24 (2), p513-529. doi:10.1287/orsc.1120.0741

Striukova, L. and Rayna, T. (2008). The role of social capital in virtual teams and organisations: Corporate Value Creation. International Journal of Networking and Virtual Organisations. 5 (1), p103-119. doi:10.1504/IJNVO.2008.016005

Walker, S. (2012). Employee Engagement \& Communication Research: Measurement Strategy \& Action. London: Kogan Page. 